\title{
Analysis and Optimization of UAV Frame Design for Manufacturing from Thermoplastic Materials on FDM 3D Printer
}

\author{
IVAN PALINKAS ${ }^{1}$, JASMINA PEKEZ ${ }^{1}$, ELEONORA DESNICA ${ }^{1}$, ALEKSANDAR RAJIC ${ }^{2}$, \\ DORIAN NEDELCU ${ }^{3 *}$ \\ ${ }^{1}$ University of Novi Sad, Technical Faculty "Mihajlo Pupin", Djure Djakovica bb, 23000 Zrenjanin, Republic of Serbia \\ ${ }^{2}$ Technical College of Applied Sciences, Djordja Stratimirovica 23, 23000 Zrenjanin, Republic of Serbia \\ ${ }^{3}$ Department of Engineering Science, Babes-Bolyai University, 1-4 Traian Vuia Sq., 320085, Resita, Romania
}

Abstract: Thermoplastic materials have great usage through FDM 3D printing technology. Today, FDM $3 D$ printer is available to the broad population, and some of the thermoplastic materials is widely used due to their small price and availability. Such thermoplastic materials are ABS (Acrylonitrile butadiene styrene) and PLA (Polylactic acid). In this paper the possibility of drone frame design optimization that can be made from ABS and PLA plastics using FDM 3D printing technology is analyzed.

Keywords: thermoplastic material, ABS, PLA, design optimization, $3 D$ printing

\section{Introduction}

Unmanned aerial vehicles (UAV) or air drones are flying robots that can be autonomous or remotely controlled by an operator from the ground. Their classification and application today is very wide. For that reason, they are subjected to extensive research and development, from design of body, design of components, development of control methods, energy efficiency improvements, etc.

Drones have their application in civil and military sector. They are very versatile vehicles and can be equipped to do various tasks from making videos and pictures or gathering data with sensors to applying pesticides in agriculture [1-4]. Figure 1 show classification of application depending on different criteria such as flight space, purpose and environment.

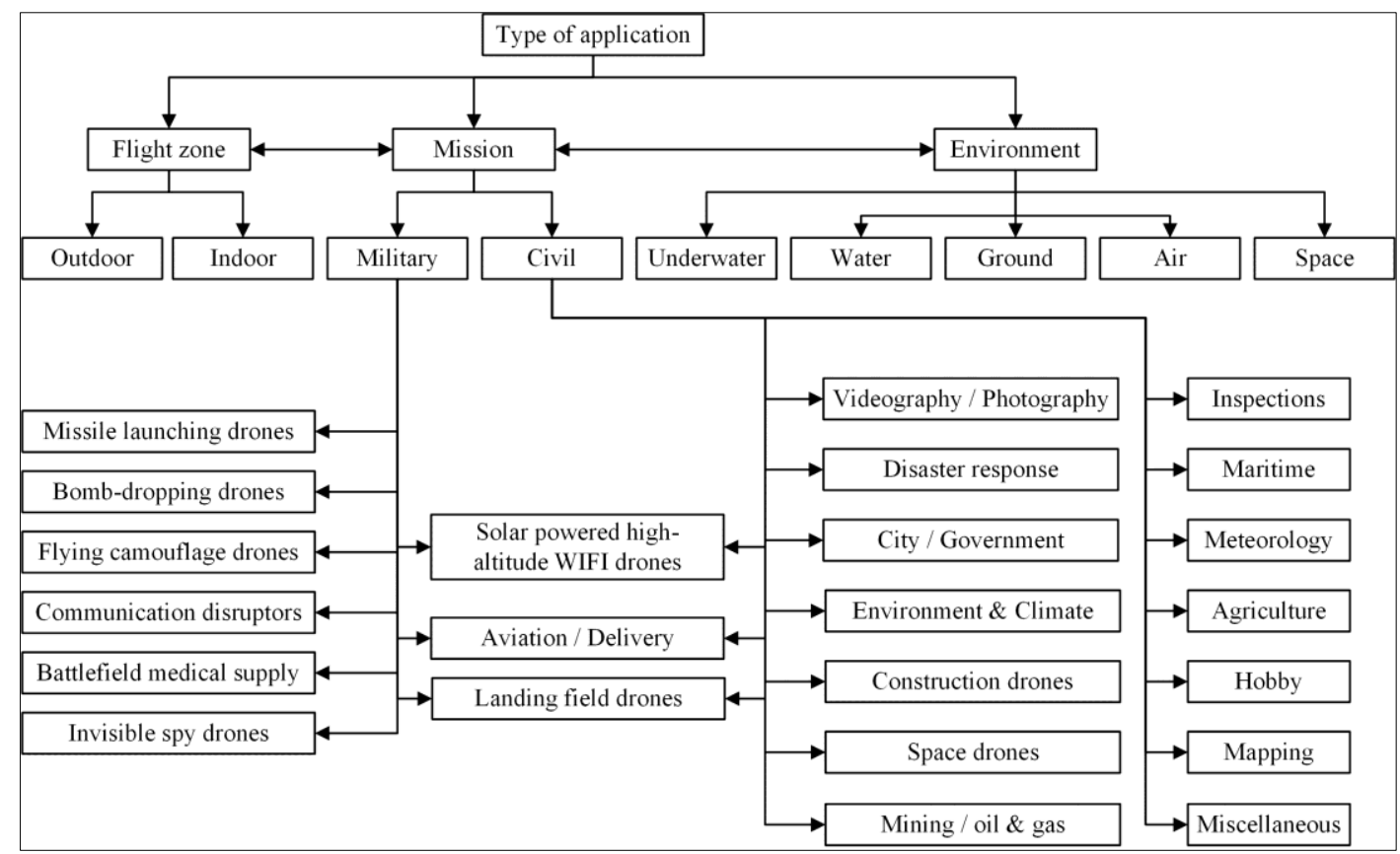

Figure 1. Classification of drones' applications [2]

*email: dorian.nedelcu@ubbcluj.ro 
In drone design and manufacturing different material and technologies are used. There are several development directions: creating new materials or applying current materials in order to achieve lightweight frame or to increase frame strength [5,6], usage of additive manufacturing technologies [711], optimizing the created design [12-14], working on sustainable design [15,16], etc. In all papers, weight is considered as crucial factor in frame design.

Mohamed M. ElFaham et al [5] work on creation of different composite densities of carbon fiber prepared via vacuum bag technique. The goal was to get lightweight and high strength material in order to get substitute for metal from which military drones are made.

Akif Mosaddek et al [15] are using recycled plastic from bottles (Polyethylene terephthalate - PET) and compare it to with the most commonly used 3D printing filaments which has proven to be effective in use for manufacturing foldable UAV frame. The purpose is to reduce environmental pollution with plastics without any loss to UAV functionality.

The advantage of using additive manufacturing (AM) in UAVs is shown by Goh et al [17], where is explained that AM technology brings to life complex designs that can't be achieved via conventional technologies. AM can use vide variety of materials and technologies in order to achieve cost effective products. Also, AM is used to improve the structural characteristics of UAV, through manufacturing the optimized design (with various optimization methods) to achieve lightweight structure with selected material, or with usage of high-strength-to-weight ratio materials (composite materials).

For the drone to fly, it must generate enough upward trust to lift itself. Selection of material, in that case, depends on drone mass.

"Every gram of material used to make a drone costs energy to lift, and every gram that can be saved improves performance: Increased cargo capacity; Extended flying time; Reduced inertia and improved maneuverability" [18].

For commercial drones, thermoplastics (nylon, polyester, and polystyrene) are popular choices because they are cheap to make into complex parts using injection molding [18]. Also, with expansion of 3D printing, used materials are ABS (Acrylonitrile butadiene styrene) and PLA (Polylactic acid) plastics, with high availability and low cost. ABS is fossil-based polymer, and as such, have significant long-term consequences on the health and the environment, while PLA is made from renewable sources (corn starch) and has potential to substitute fossil-based polymers (low melting point of PLA requires less energy, compared to ABS) [19]. For industrial application, carbon-fiber material is most used due to high strength to weight ratio.

Development of 3D printing technology allowed applications in manufacturing complex geometries in various areas: medicine [20], hydrodinamics [21], etc. Because of that development it has become available to design and manufacture drone bodies with unique designs and for specific purpose. And with that in mind, the design of body of quadcopter (or quadrotor) with the characteristics of two plastic material (PLA and ABS), that are commonly used in FDM 3D printing technology, is analyzed and optimized in this paper, for the purpose of reducing mass of drone to decrease energy consumption.

\section{Materials and methods}

Overall design of rotary wing drones is influenced by drone application. Frame design is based on number and position of motors. On Figure 2 and Figure 3 the example of quadcopter frame configuration is shown.

Cross configuration is most common in usage. The ring configuration is more rigid.

Rotary wing drones generally have problem with endurance because of higher power for hovering flight mode requirements. In design of this type of UAV the weight is important criterion [2]. That's why many researchers investigate different types of materials, technologies and shape in order to achieve minimal weight of drone frame. 


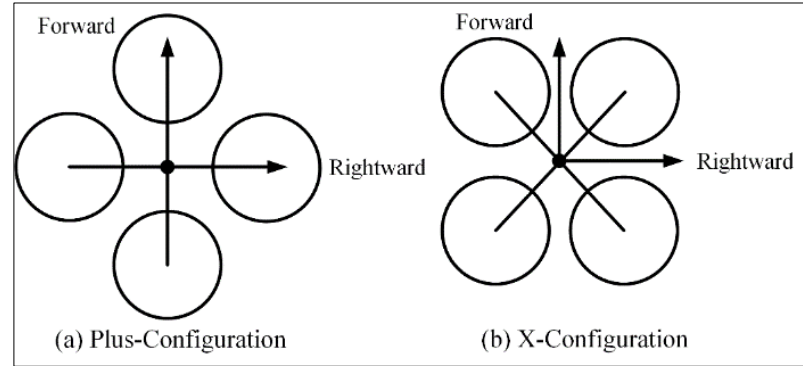

Figure 2. Cross configuration [22]

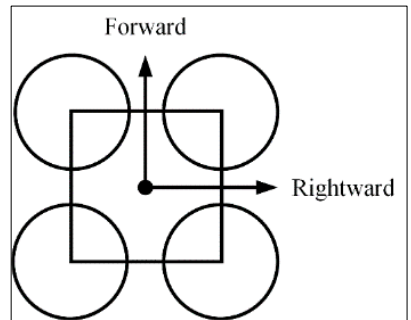

Figure 3. Ring configuration [22]

Within this paper the thermoplastic materials for the usage with FDM 3D printing technology is used for design of X-configuration of quadcopter.

Fused Deposition Modeling is, in technological sense, on somewhat lower level than other AM technologies. FDM process forms solid models, extruding and depositing liquid thermoplastic material in layers on moving platform. Extrusion of materials is done on temperature lower than melting point of thermoplastic material. The temperature of the platform is lower than temperature of nozzle (extrusion is done via extruder head and nozzle) so that thermoplastic rapidly hardens. FDM process is relatively simple but it is constricted to thermoplastic materials and wax for precise casting [20,23].

With the availability of commercial 3D printers today, everyone can manufacture desired parts. As said, the most common used materials are Polylactic Acid (PLA) and Acrylonitrile Butadiene Styrene (ABS) plastics. Therefore, analysis is conducted on models with various shapes in order to see what material provides wider space for design improvements.

Research goal is to reduce weight of UAV frame by optimizing the model design and to determine the dimensional influence of defined parameters regardless of UAV arm cross section shape.

\subsection{Numerical experiment}

Study flow for experiment is shown on Figure 4.

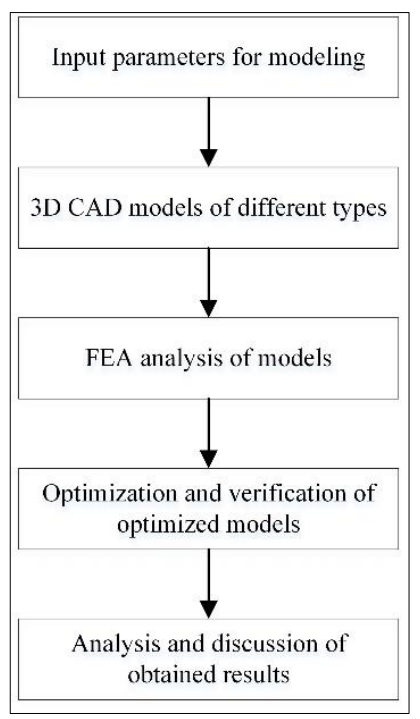

Figure 4. Study flow chart

First step in the experiment is modeling of quadcopter drone frame. From that it can be determined the drone frame span, size of propellers and motor thrust. For this case, the overall weight of drone is around $5 \mathrm{~kg}$, with frame span of 500mm and with $2: 1$ thrust. For analysis purpose only one arm is used. Length of the arm is $225 \mathrm{~mm}$. The initial parameter that must be taken in consideration is overall weight of drone. On model we are using the combination of three geometrical shapes (circle, square and hexagon) on four cross sections of drone arm. Initial dimensions of observed parameters (P1-P4) are: 
for circle - diameter $=15 \mathrm{~mm}$; for square - square side $=15 \mathrm{~mm}$; hexagon - inscribed in circle diameter $=15 \mathrm{~mm}$.

Parameters used for optimization are dimensions of corresponding cross section (cross section 1 parameter $\mathrm{P} 1$; cross section 2 - parameter $\mathrm{P} 2$; cross section 3 - parameter $\mathrm{P} 3$; cross section 4 - parameter P4) from 11-20mm (lower value is determined by the opening for cables from motor in the center of model cross section). Cross sections are positioned from center of drone to motor, on $50 \mathrm{~mm}$ mutual distance (Figure 5).

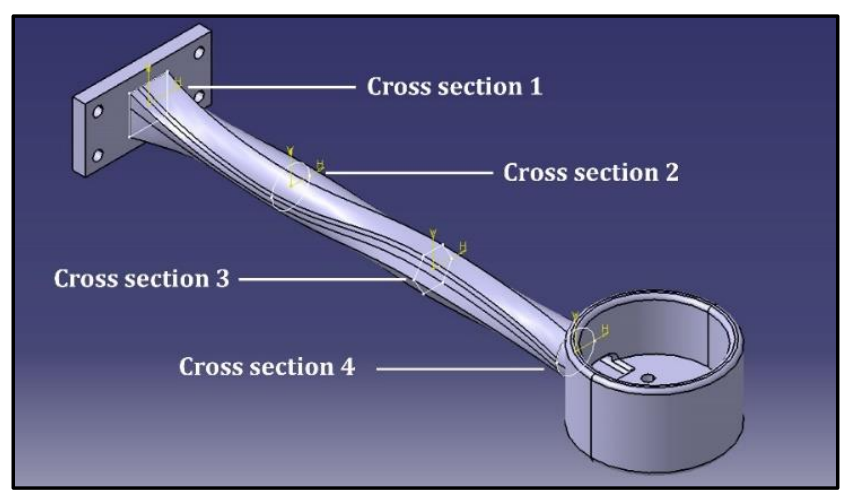

Figure 5. Positions and different types of cross sections on quadcopter arm

\subsection{FEA analysis}

For analysis two different materials were used: PLA and ABS (characteristics of materials used in analysis are shown in Table 1). Materials were selected as they are most used plastic materials in commercial 3D printing technology.

Table 1. Typical properties of plastic materials used for analysis [24,25]

\begin{tabular}{|c|c|c|c|c|}
\hline Parameter & Symbol & Unit & Polylactic Acid (PLA) & $\begin{array}{c}\text { Acrylonitrile Butadiene } \\
\text { Styrene (ABS) }\end{array}$ \\
\hline Young Modulus & $\mathrm{E}$ & $\frac{\mathrm{N}}{\mathrm{m}^{2}}$ & $2.87 \times 10^{9}-3.58 \times 10^{9}$ & $1.50 \times 10^{9}-3.14 \times 10^{9}$ \\
\hline Poisson Ratio & $v$ & - & 0.36 & 0.38 to 0.40 \\
\hline Density & $\rho$ & $\frac{\mathrm{kg}}{\mathrm{m}^{3}}$ & $1.24 \times 10^{3}-1.25 \times 10^{3}$ & $1.03 \times 10^{3}-1.08 \times 10^{3}$ \\
\hline $\begin{array}{c}\text { Thermal } \\
\text { expansion }\end{array}$ & $\alpha$ & $\frac{1}{\mathrm{~K}}$ & $6.8 \times 10^{-11}$ & $7.92 \times 10^{-11}-9.54 \times 10^{-11}$ \\
\hline \begin{tabular}{c} 
Yield strength \\
\hline
\end{tabular} & $\mathrm{R}$ & $\frac{\mathrm{N}}{\mathrm{m}^{2}}$ & $15.51 \times 10^{6}-71.71 \times 10^{6}$ & $29.03 \times 10^{6}-57.02 \times 10^{6}$ \\
\hline
\end{tabular}

Static analysis was conducted on ten different shapes (Figure 6) listed in Table 2.

Table 2. Types of analysis shapes

\begin{tabular}{|c|c|}
\hline Type & Cross sections \\
\hline Type 1 & Circle-Circle-Circle-Circle \\
\hline Type 2 & Square-Square-Square-Square \\
\hline Type 3 & Hexagon-Hexagon-Hexagon-Hexagon \\
\hline Type 4 & Square-Circle-Hexagon-Circle \\
\hline Type 5 & Hexagon-Circle-Square-Hexagon \\
\hline Type 6 & Square-Hexagon-Circle-Square \\
\hline Type 7 & Hexagon-Square-Circle-Circle \\
\hline
\end{tabular}




\begin{tabular}{|c|c|}
\hline Type 8 & Square-Hexagon-Square-Hexagon \\
\hline Type 9 & Circle-Square-Square-Circle \\
\hline Type 10 & Circle-Hexagon-Square-Hexagon \\
\hline
\end{tabular}
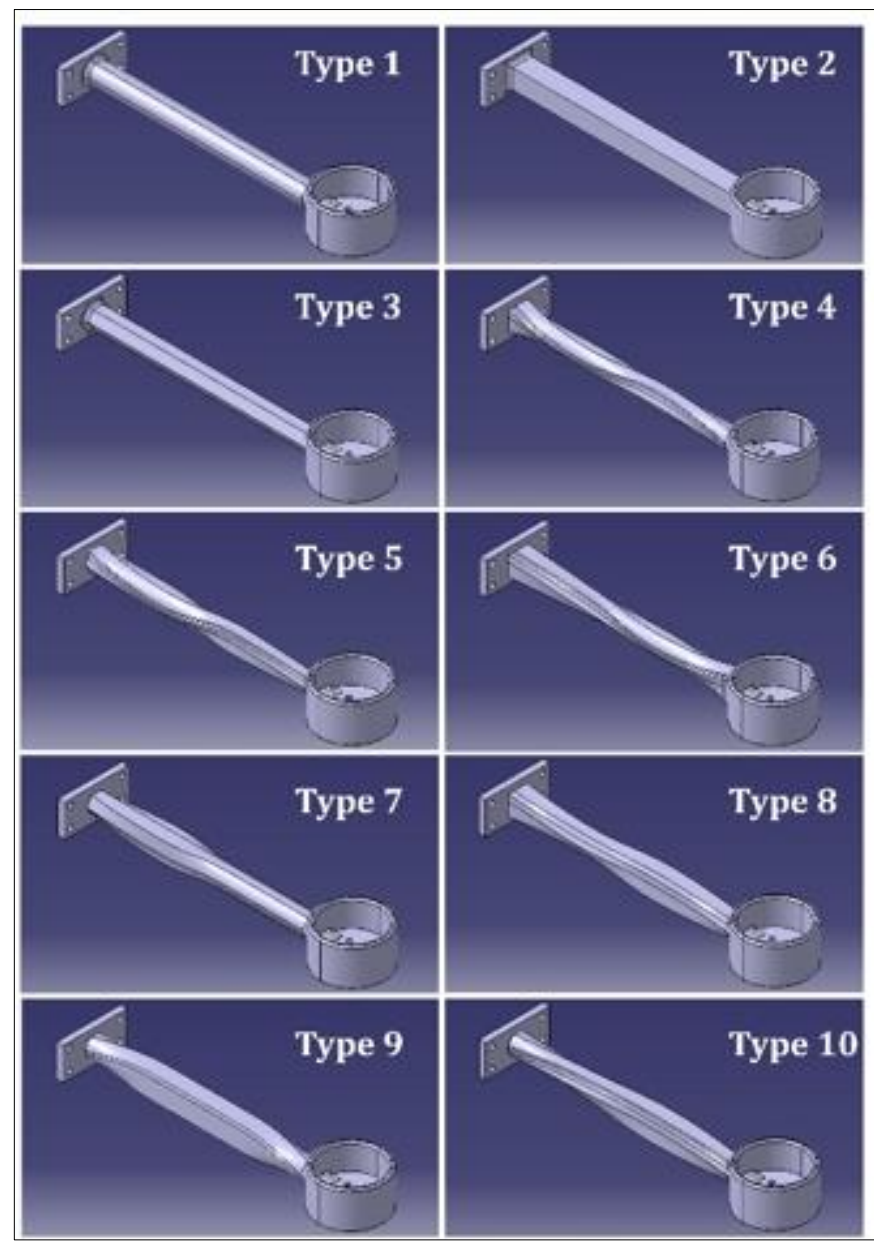

Figure 6. Graphic view of analyzed model types

Models were analyzed for static load for drone take off. Value of static load is $6.377 \mathrm{~N}$, and it is positioned vertical upwards. Mesh elements are shown in Table 3. Results of simulation, on Type 3 with ABS material

Results of simulation are shown on Figures 7 - 10, on example using Type 3 model and ABS material.

Table 3. Mesh properties

\begin{tabular}{|c|c|}
\hline Type of mesh & OCTREE Tetrahedron mesh \\
\hline Type of element & Linear \\
\hline Size of element & $14.388 \mathrm{~mm}$ \\
\hline Absolute sag & $2.302 \mathrm{~mm}$ \\
\hline Criteria & Shape \\
\hline Jacobian & 0.3 \\
\hline Warp & 60 \\
\hline Geometry size limit & $0.1 \mathrm{~mm}$ \\
\hline
\end{tabular}




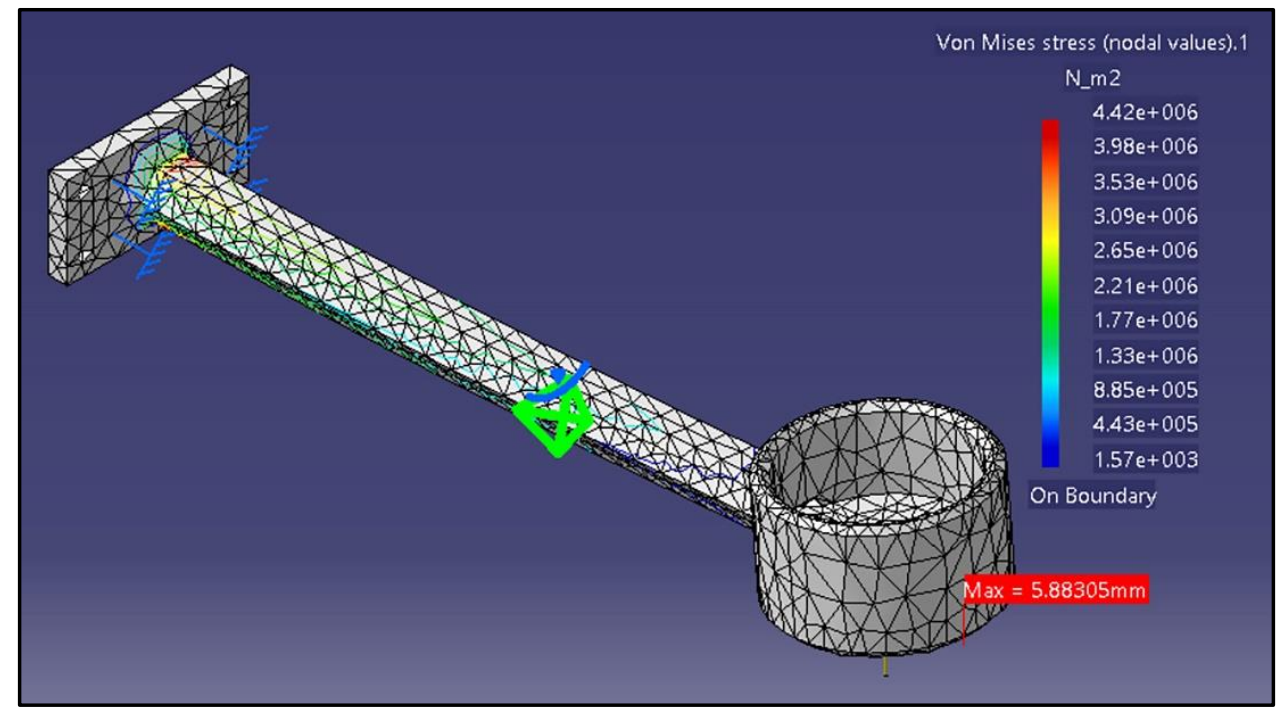

Figure 7. Example of initial model analysis (Type 3 - ABS material) - Von Mises stress

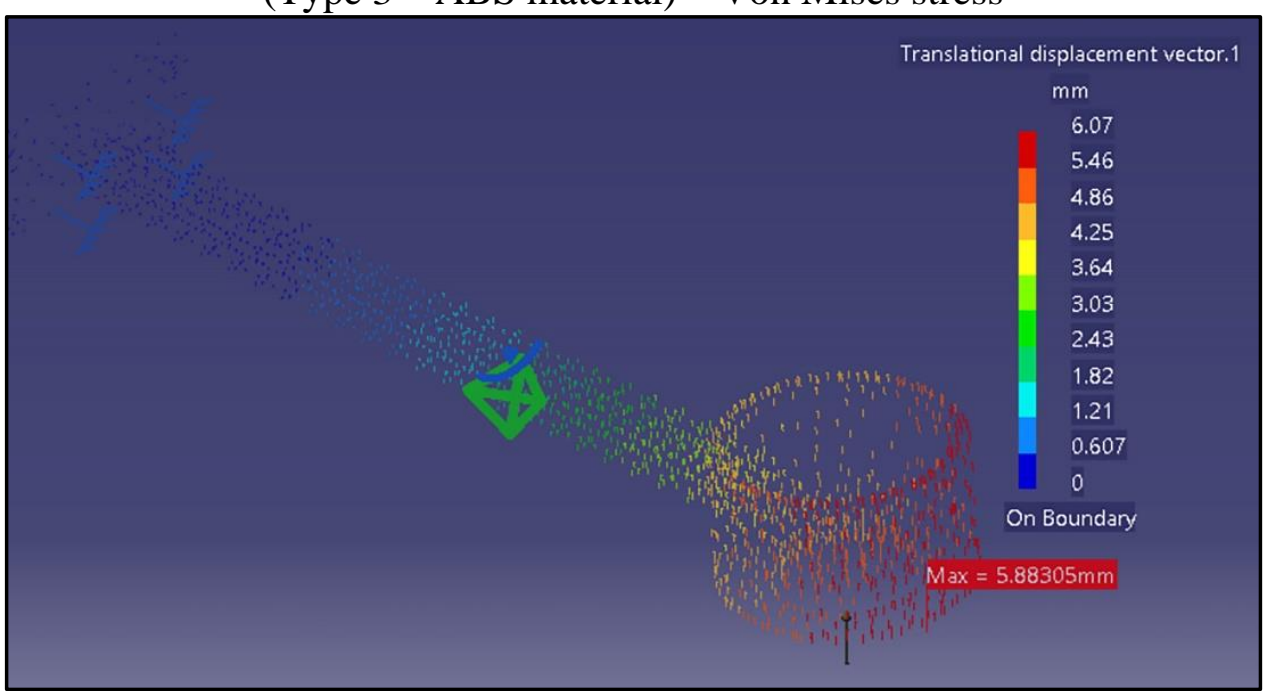

Figure 8. Example of initial model analysis (Type 3-ABS material) - Translational displacement vector

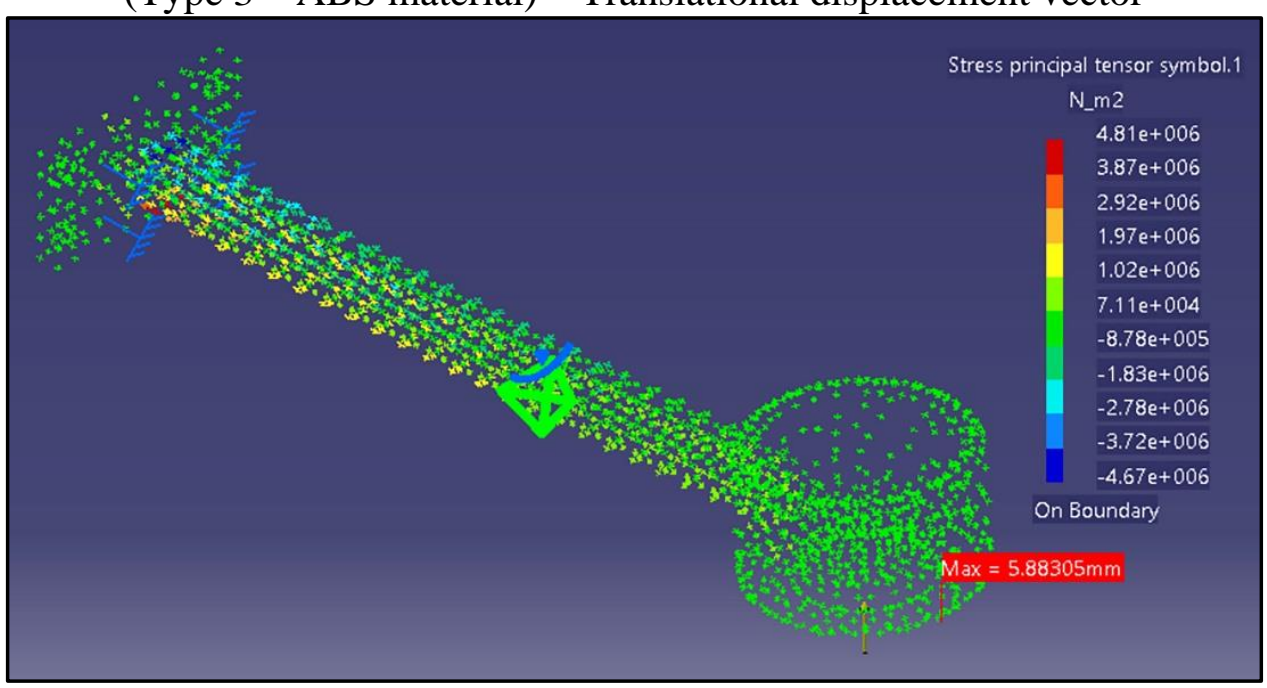

Figure 9. Example of initial model analysis

(Type 3 - ABS material) - Stress principal tensor symbol 


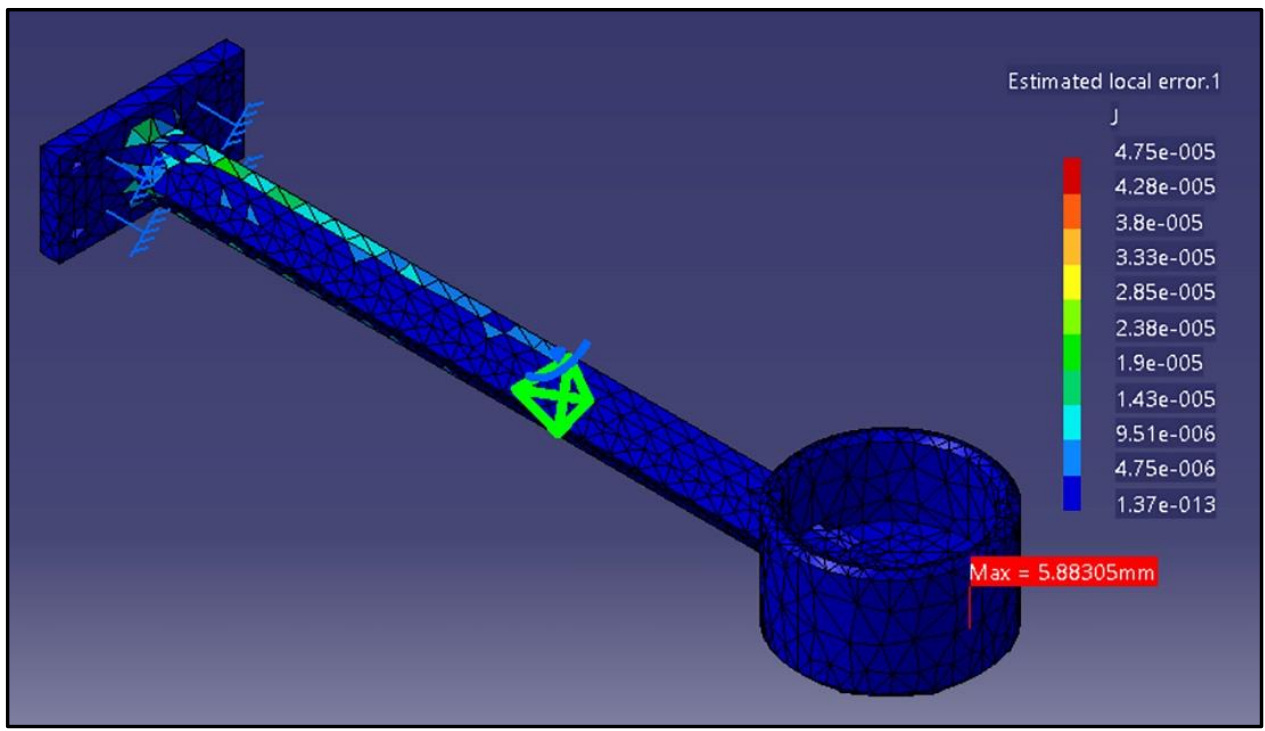

Figure 10. Example of initial model analysis

(Type 3 - ABS material) - Estimated local error

\subsection{Optimization process of model design}

After verification of models design, optimization was done. Process of optimization was done by Catia Product Engineering Optimizer. Input parameters were parameters P1 - P4 (in range 11-20mm) and output constraints were volume and displacement. Displacement is measured by using local sensor set on lower plate of motor position. Example of displacement value is shown on Figures 7 - 10 (for this type displacement value was $5.88305 \mathrm{~mm}$ ). The goal was set for: volume less than $30000 \mathrm{~mm}^{3}$, and displacement equal to zero. The goal for both constraints cannot be achieved but optimization will bring values as close as possible. The applied algorithm for optimization process is Simulated Annealing Algorithm.

\section{Results and discussions}

There are two results of optimization used for consideration for each model:

- Minimal volume value (Min. Vol.) of model with some decrease of displacement;

- Minimal displacement value (Min. Displ.) of model with some decrease of volume.

Results obtained through process of optimization are shown in Table 4 (for PLA material) and in Table 5 (for ABS material). In this two tables, beside the optimized results, there are also shown the initial values (IV) obtained through analysis before optimization.

Table 4. Results of model optimization for PLA material

\begin{tabular}{|c|c|c|c|c|c|c|c|c|}
\hline \multicolumn{2}{|c|}{ Model } & P1 $(\mathrm{mm})$ & P2 $(\mathrm{mm})$ & P3 $(\mathrm{mm})$ & P4 $(\mathrm{mm})$ & Displacement $(\mathrm{mm})$ & Volume $\left(\mathrm{mm}^{3}\right)$ & Mass (g) \\
\hline \multirow{3}{*}{ Type 1 } & IV & 15 & 15 & 15 & 15 & 2.43 & 59752.84 & 74.09 \\
\cline { 2 - 10 } & Min. Vol. & 16.48 & 15.25 & 13.95 & 11.15 & 2.43 & 57189.23 & 70.91 \\
\cline { 2 - 9 } & Min. Displ. & 18.95 & 15.35 & 13.95 & 13.14 & 2.12 & 59740.11 & 74.08 \\
\hline \multirow{3}{*}{ Type 2 2 } & IV & 15 & 15 & 15 & 15 & 1.23 & 68206.75 & 84.58 \\
\cline { 2 - 9 } & Min. Vol. & 15.01 & 16.40 & 13.13 & 12.58 & 1.23 & 65684.86 & 81.45 \\
\cline { 2 - 9 } & Min. Displ. & 16.03 & 16.03 & 14.21 & 12.58 & 1.10 & 67537.22 & 83.75 \\
\hline \multirow{3}{*}{ Type 3 3 } & IV & 15 & 15 & 15 & 15 & 3.20 & 54325.23 & 67.36 \\
\cline { 2 - 9 } & Min. Vol. & 16.64 & 15.59 & 12.96 & 11.02 & 3.17 & 51563.95 & 63.94 \\
\cline { 2 - 9 } & Min. Displ. & 17.35 & 16.25 & 13.41 & 13.38 & 2.64 & 54305.37 & 67.34 \\
\hline \multirow{3}{*}{ Type 4 4 } & IV & 15 & 15 & 15 & 15 & 2.97 & 55621.79 & 68.97 \\
\cline { 2 - 9 } & Min. Vol. & 18.33 & 15.70 & 13.61 & 11.00 & 2.81 & 54820.28 & 67.98 \\
\cline { 2 - 9 } & Min. Displ. & 18.33 & 15.70 & 13.61 & 11.00 & 2.81 & 54820.28 & 67.98 \\
\hline \multirow{3}{*}{ Type 5 } & IV & 15 & 15 & 15 & 15 & 3.13 & 59156.94 & 73.35 \\
\cline { 2 - 9 } & Min. Vol. & 15.65 & 16.12 & 11.44 & 15.86 & 2.94 & 55948.31 & 69.38 \\
\cline { 2 - 8 } & Min. Displ. & 15.84 & 17.35 & 11.99 & 15.58 & 2.39 & 58435.41 & 72.46 \\
\hline
\end{tabular}




\begin{tabular}{|c|c|c|c|c|c|c|c|c|}
\hline \multirow{3}{*}{ Type 6 } & IV & 15 & 15 & 15 & 15 & 2.48 & 58249.65 & 72.23 \\
\cline { 2 - 9 } & Min. Vol. & 13.29 & 17.51 & 13.25 & 11.08 & 2.46 & 55776.63 & 69.16 \\
\cline { 2 - 9 } & Min. Displ. & 13.81 & 18.14 & 14.03 & 11.54 & 2.04 & 58214.70 & 72.19 \\
\hline \multirow{3}{*}{ Type 7 } & IV & 15 & 15 & 15 & 15 & 1.87 & 61875.27 & 76.73 \\
\cline { 2 - 10 } & Min. Vol. & 19.09 & 14.49 & 14.56 & 12.14 & 1.71 & 60653.13 & 75.21 \\
\cline { 2 - 9 } & Min. Displ. & 19.03 & 14.69 & 15.13 & 12.13 & 1.57 & 61807.24 & 76.64 \\
\hline \multirow{3}{*}{ Type 8 } & IV & 15 & 15 & 15 & 15 & 2.66 & 57872.89 & 71.76 \\
\cline { 2 - 10 } & Min. Vol. & 14.20 & 15.95 & 13.31 & 15.52 & 2.61 & 56108.69 & 69.57 \\
\cline { 2 - 9 } & Min. Displ. & 15.66 & 18.30 & 11.64 & 16.19 & 2.03 & 57797.35 & 71.67 \\
\hline \multirow{3}{*}{ Type 9 9} & IV & 15 & 15 & 15 & 15 & 1.87 & 63854.95 & 79.18 \\
\cline { 2 - 10 } & Min. Vol. & 16.60 & 15.14 & 12.90 & 14.67 & 1.83 & 60652.75 & 75.21 \\
\cline { 2 - 9 } & Min. Displ. & 19.76 & 15.92 & 12.85 & 15.14 & 1.44 & 63739.71 & 79.04 \\
\hline \multirow{3}{*}{ Type 10 10} & IV & 15 & 15 & 15 & 15 & 2.97 & 59533.68 & 73.82 \\
\cline { 2 - 9 } & Min. Vol. & 19.11 & 14.89 & 11.36 & 16.14 & 2.76 & 55762.04 & 69.14 \\
\cline { 2 - 9 } & Min. Displ. & 18.01 & 18.63 & 11.84 & 12.54 & 1.77 & 59420.08 & 73.68 \\
\hline
\end{tabular}

From Table 4 it can be seen that volume values of initial model vary from $54325.23-68206.75 \mathrm{~mm}^{3}$, and displacement value of initial model vary from $1.23-3.20 \mathrm{~mm}$, both depending of model type. From used PLA material characteristics, the calculated mass of initial models varies from 67.36 - 84.58g. With optimization, new achieved volume has range from $51563.95-65684.86 \mathrm{~mm}^{3}$ with displacement values from $1.23-3.17 \mathrm{~mm}$ (for cases with minimal volume value), and for cases with minimal displacement, the volume varies from $54305.37-67537.22 \mathrm{~mm}^{3}$, and displacement from $1.10-2.64 \mathrm{~mm}$. Mass of the drone arm in both cases is $63.94-81.45 \mathrm{~g}$ (for minimal volume) and $67.34-83.75 \mathrm{~g}$ (for minimal displacement).

Table 5. Results of model optimization for ABS material

\begin{tabular}{|c|c|c|c|c|c|c|c|c|}
\hline \multicolumn{2}{|c|}{ Model } & $\mathrm{P} 1(\mathrm{~mm})$ & $\mathrm{P} 2(\mathrm{~mm})$ & P3 (mm) & $\mathrm{P} 4(\mathrm{~mm})$ & Displacement (mm) & Volume $\left(\mathrm{mm}^{3}\right)$ & Mass (g) \\
\hline \multirow{3}{*}{ Type 1} & IV & 15 & 15 & 15 & 15 & 4.44 & 59752.84 & 61.55 \\
\hline & Min. Vol. & 14.88 & 15.44 & 13.87 & 14.31 & 4.41 & 58282.65 & 60.03 \\
\hline & Min. Displ. & 15.03 & 15.89 & 14.20 & 13.98 & 4.16 & 59296.84 & 61.08 \\
\hline \multirow{3}{*}{ Type 2} & IV & 15 & 15 & 15 & 15 & 2.34 & 68206.75 & 70.25 \\
\hline & Min. Vol. & 15.83 & 15.35 & 13.96 & 11.12 & 2.33 & 64663.59 & 66.60 \\
\hline & Min. Displ. & 16.00 & 15.90 & 15.07 & 11.43 & 1.99 & 68148.87 & 70.19 \\
\hline \multirow{3}{*}{ Type 3} & IV & 15 & 15 & 15 & 15 & 5.88 & 54325.23 & 55.95 \\
\hline & Min. Vol. & 16.62 & 15.50 & 13.09 & 11.40 & 5.79 & 51751.14 & 53.30 \\
\hline & Min. Displ. & 15.96 & 16.85 & 13.57 & 12.76 & 4.80 & 54295.93 & 55.92 \\
\hline \multirow{3}{*}{ Type 4} & IV & 15 & 15 & 15 & 15 & 5.48 & 55621.79 & 57.29 \\
\hline & Min. Vol. & 15.88 & 14.78 & 14.96 & 14.54 & 5.46 & 55438.48 & 57.10 \\
\hline & Min. Displ. & 17.44 & 14.76 & 14.72 & 13.75 & 5.30 & 55525.83 & 57.19 \\
\hline \multirow{3}{*}{ Type 5} & IV & 15 & 15 & 15 & 15 & 5.71 & 59156.94 & 60.93 \\
\hline & Min. Vol. & 17.55 & 15.43 & 11.38 & 11.53 & 5.54 & 53440.28 & 55.04 \\
\hline & Min. Displ. & 16.47 & 17.91 & 13.12 & 11.38 & 3.76 & 59059.55 & 60.83 \\
\hline \multirow{3}{*}{ Type 6} & IV & 15 & 15 & 15 & 15 & 4.54 & 58249.65 & 60.00 \\
\hline & Min. Vol. & 13.03 & 16.76 & 14.02 & 11.17 & 4.54 & 55610.25 & 57.28 \\
\hline & Min. Displ. & 13.14 & 16.69 & 15.01 & 12.19 & 4.18 & 57442.05 & 59.17 \\
\hline \multirow{3}{*}{ Type 7} & IV & 15 & 15 & 15 & 15 & 3.43 & 61875.27 & 63.73 \\
\hline & Min. Vol. & 17.75 & 14.39 & 14.88 & 11.00 & 3.37 & 59636.11 & 61.43 \\
\hline & Min. Displ. & 18.27 & 15.02 & 15.21 & 11.41 & 2.91 & 61771.64 & 63.62 \\
\hline \multirow{3}{*}{ Type 8} & IV & 15 & 15 & 15 & 15 & 4.88 & 57872.89 & 59.61 \\
\hline & Min. Vol. & 14.47 & 17.87 & 11.67 & 11.67 & 4.43 & 54581.84 & 56.22 \\
\hline & Min. Displ. & 15.26 & 19.41 & 12.19 & 11.20 & 3.55 & 57702.95 & 59.43 \\
\hline \multirow{3}{*}{ Type 9} & IV & 15 & 15 & 15 & 15 & 3.43 & 63854.95 & 65.77 \\
\hline & Min. Vol. & 16.24 & 15.91 & 12.76 & 11.00 & 3.41 & 60128.90 & 61.93 \\
\hline & Min. Displ. & 18.10 & 15.85 & 13.23 & 12.86 & 2.82 & 62360.72 & 64.23 \\
\hline \multirow{3}{*}{ Type 10} & IV & 15 & 15 & 15 & 15 & 5.46 & 59533.68 & 61.32 \\
\hline & Min. Vol. & 19.11 & 14.89 & 11.36 & 16.14 & 5.07 & 55761.93 & 57.43 \\
\hline & Min. Displ. & 18.00 & 19.06 & 11.72 & 11.68 & 3.28 & 59527.80 & 61.31 \\
\hline
\end{tabular}

From Table 5 it can be seen that volume values of initial model vary from $54325.23-68206.75 \mathrm{~mm}^{3}$ (of course initial volume value is the same for both materials because it is not dependent on material 
characteristics) and displacement value of initial model vary from $2.34-5.88 \mathrm{~mm}$. From used ABS material characteristics, the calculated mass of initial models varies from 55.95 - $70.25 \mathrm{~g}$. With optimization, new achieved volume has range from $51751.14-64663.59 \mathrm{~mm}^{3}$ with displacement values from $2.33-5.79 \mathrm{~mm}$ (for cases with minimal volume value), and for cases with minimal displacement, the volume varies from $54295.93-68148.87 \mathrm{~mm}^{3}$, and displacement from $1.99-4.80 \mathrm{~mm}$. Mass of the drone arm in both cases is $53.30-66.60 \mathrm{~g}$ (for minimal volume) and $55.92-70.19 \mathrm{~g}$ (for minimal displacement).

For further analysis, Table 6 that shows arithmetic mean values of obtained results, will be used.

Table 6. Arithmetic mean values of displacement, volume and mass of initial and optimized models for PLA and ABS materials

\begin{tabular}{|c|c|c|c|c|c|}
\hline & \multicolumn{5}{|c|}{ Arithmetic mean values } \\
\hline Material & $\begin{array}{c}\text { Displacement } \\
(\mathrm{mm})\end{array}$ & $\begin{array}{c}\text { Minimal } \\
\text { displacement } \\
(\mathrm{mm})\end{array}$ & $\begin{array}{c}\text { Maximal } \\
\text { displacement } \\
(\mathrm{mm})\end{array}$ & $\begin{array}{c}\text { Minimal displacement } \\
\text { decrease }(\mathrm{mm})\end{array}$ & $\begin{array}{c}\text { Maximal displacement } \\
\text { decrease }(\mathrm{mm})\end{array}$ \\
\hline PLA & 2.481 & 1.991 & 2.395 & 0.086 & 0.49 \\
\hline ABS & 4.559 & 3.675 & 4.435 & 0.124 & 0.884 \\
\hline Material & $\begin{array}{c}\text { Volume } \\
\left(\mathrm{mm}^{3}\right)\end{array}$ & $\begin{array}{c}\text { Minimal volume } \\
\left(\mathrm{mm}^{3}\right)\end{array}$ & $\begin{array}{c}\text { Maximal volume } \\
\left(\mathrm{mm}^{3}\right)\end{array}$ & $\begin{array}{c}\text { Minimal volume decrease } \\
\left(\mathrm{mm}^{3}\right)\end{array}$ & $\begin{array}{c}\text { Maximal volume } \\
\text { decrease }\left(\mathrm{mm}^{3}\right)\end{array}$ \\
\hline PLA & 59844.999 & 57415.987 & 59581.747 & 263.252 & 2429.012 \\
\hline ABS & 59844.999 & 56929.517 & 59513.218 & 331.781 & 2915.482 \\
\hline Material & $\begin{array}{c}\text { Mass } \\
(\mathrm{g})\end{array}$ & Minimal mass $(\mathrm{g})$ & Maximal mass $(\mathrm{g})$ & $\begin{array}{c}\text { Minimal mass decrease } \\
(\mathrm{g})\end{array}$ & $\begin{array}{c}\text { Maximal mass decrease } \\
(\mathrm{g})\end{array}$ \\
\hline PLA & 74.207 & 71.195 & 73.883 & 0.324 & 3.012 \\
\hline ABS & 61.64 & 58.636 & 61.297 & 0.343 & 3.004 \\
\hline
\end{tabular}

In Table 6 minimal displacement is connected with maximum volume (or mass) (model with maximal volume value after optimization have minimal displacement value) and vice versa.

As shown in Table 6, optimized model has been achieved. The goal was to obtain model with reduced weight and reduced displacement of drone arm bending. In the terms of material used for model analysis:

- In initial models PLA have greater mass then ABS, but smaller displacement (volume of models is the same for both materials)

-In optimized models with ABS have greater volume and displacement reduction than PLA, but in term of mass that reduction is approximately the same.

-In optimized model, ABS still have the greater displacement value than PLA.

For this analysis, the model used is designed with four parameters (P1-P4). By changing their value, the optimal model design can be achieved. In Figures 11 - 14 optimized values of parameters for analyzed models are shown.

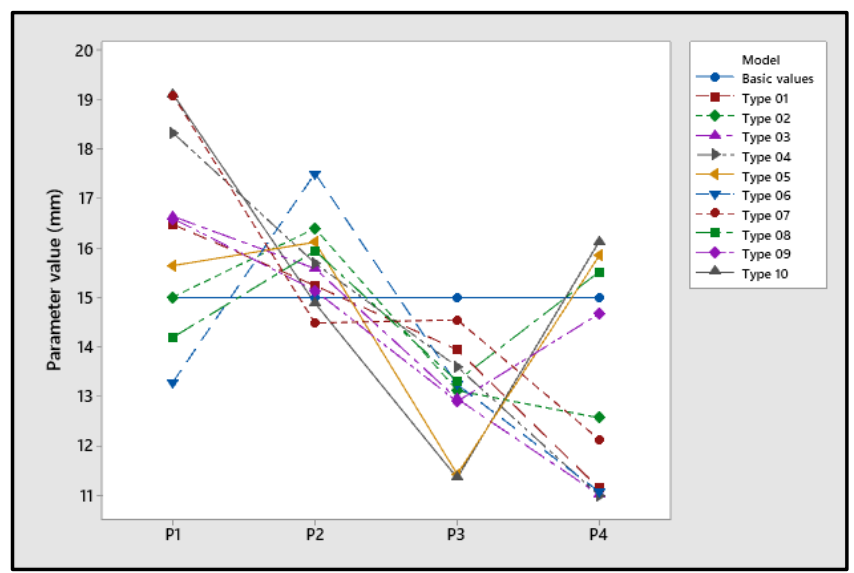

Figure 11. Parameter value for maximum volume decrease of PLA model 


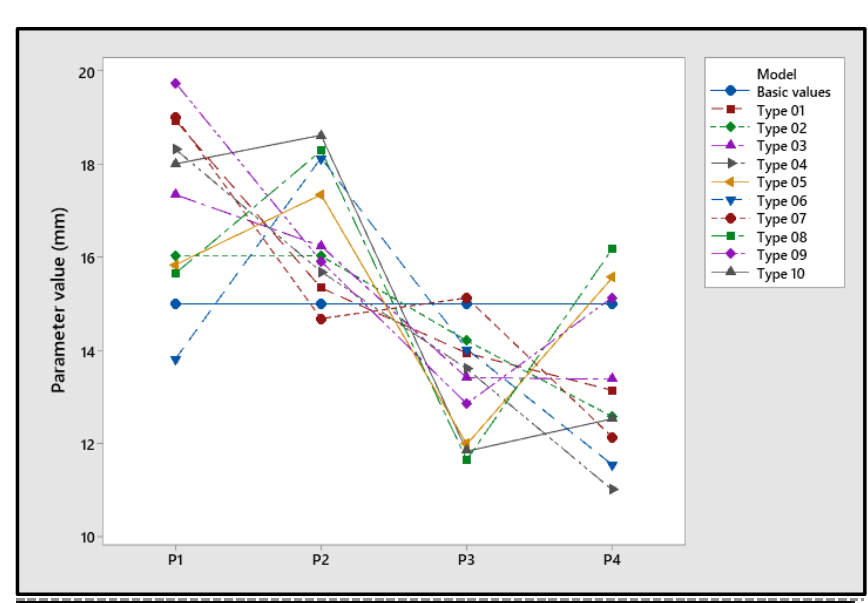

Figure 12. Parameter value for maximum displacement decrease of PLA model

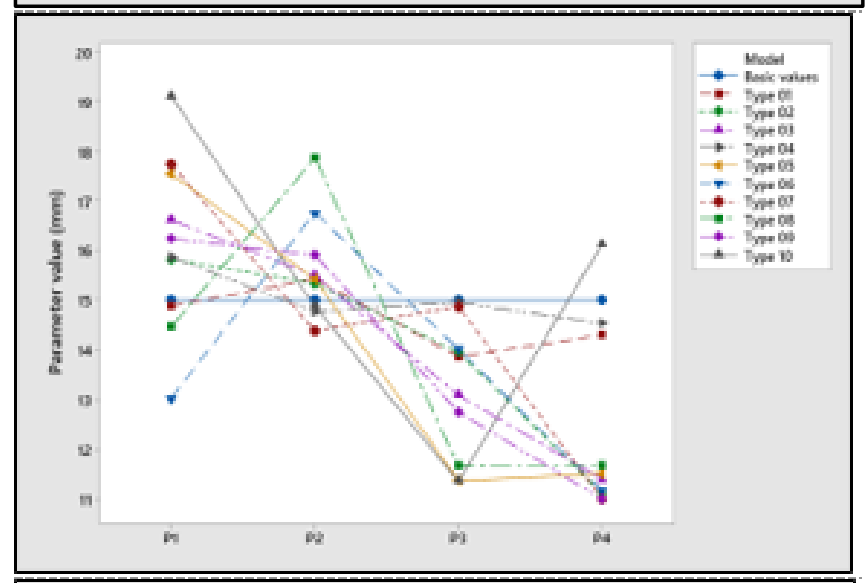

Figure 13. Parameter value for maximum volume decrease of ABS model

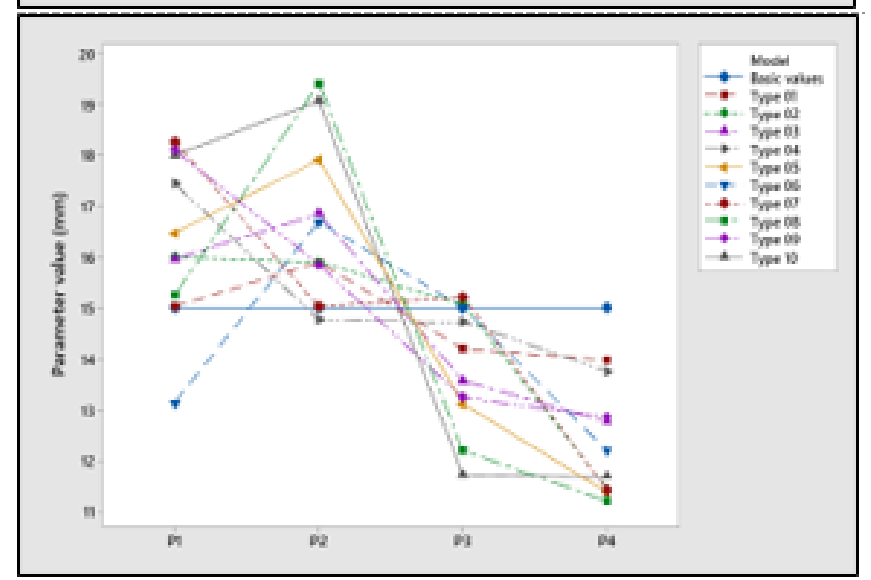

Figure 14. Parameter value for maximum displacement decrease of ABS model

In all four cases with the analysis of all ten optimized types the most values of parameters P1 and P2 are increased and the parameters $\mathrm{P} 3$ and $\mathrm{P} 4$ are decreased. In the comparison between two materials for PLA is dominant increase is in parameter P1 while for ABS is parameter P2 (through comparison of parameters P1 and P2), and the dominant decrease for PLA is parameter P3 and for ABS is parameter $\mathrm{P} 4$. This comparison is based for the values of parameters in each model type.

\section{Conclusions}

Due wide usage of drones today and rising trends in energy efficiency of any vehicle, mass is important factor for energy consumption. There are several ways to reduce mass of drone, without impact to its functionality. One of them is optimizing drone frame. Most of the work in this field is by improvement of materials. So here, we are analyzing improvement in design of complex geometry with regards to existing materials.

In this paper, the optimization of drone arm was conducted. The analysis was performed on models of drone arm with different shape construction, and for PLA and ABS thermoplastic materials in order 
to be possible to make drone arm with 3D printing.

Used shape construction consists of basic geometric shapes in 4 intersections with different shapes layout, there for, obtaining different complex 3D shapes for analysis. Optimization is conducted on that different complex 3D shapes through dimensional change of basic geometric shapes. The purpose of this research is to determine if there is any observed pattern of dimensional parameter changes in order to provide best design practice for creation of drone frame, with achieving freeform model, in regard to two most used plastic material for FDM 3D printing.

Through optimization, by changing the parameter values of drone arm cross section design in order to produce drone with lesser mass, it has been achieved the decrease of volume while retaining rigidity of frame or even increase rigidity. As discussed, from parameters P1-P4 point of view, the reduced volume is achieved in all the models with general increase of parameter P1 and general decrease of parameter $\mathrm{P} 3$ and $\mathrm{P} 4$.

In the comparison of PLA and ABS materials, used in design optimization, decrease of mass value is the almost the same. ABS provides lesser initial mass than PLA, but PLA gives greater rigidity of frame.

For the future research the idea is to obtain mathematical model of parameter changes due to different material and different complex geometry shapes for design improvement and mass reduction without changes to frame rigidity.

\section{References}

1.ALBEAINO, G., GHEISARI, M., FRANZ B.W., A systematic review of unmanned aerial vehicle application areas and technologies in the AEC domain, ITcon., 24, 2019, 381-405.

2.HASSANALIAN, M., ABDELKEFI, A., Classifications, applications, and design challenges of drones: A review, Prog. Aerosp. Sci., 91, 2017, 99-131.

http://dx.doi.org/10.1016/i.paerosci.2017.04.003

3.FENNELLY, L.J., PERRY, M.A. Unmanned Aerial Vehicle (Drone) Usage in the 21st Century, The Professional Protection Officer (Second Edition). 2020. 183-189.

https://doi.org/10.1016/B978-0-12-817748-8.00050-X

4.SHAKHATREH, H., SAWALMEH, A.H., AL-FUQAHA, A., DOU, Z., ALMAITA, E., KHALIL, I., OTHMAN, N.S., KHREISHAH, A., GUIZANI, M., Unmanned Aerial Vehicles (UAVs): A Survey on Civil Applications and Key Research Challenges, IEEE Access, 7, 2019, 48572-48634.

doi: 10.1109/ACCESS.2019.2909530

5.ELFAHAM, M.M., MOSTAFA, A.M., NASR, G.M., Unmanned aerial vehicle (UAV) manufacturing materials: Synthesis, spectroscopic characterization and dynamic mechanical analysis (DMA), J. Mol. Struct., 1201, 2020, 127211. https://doi.org/10.1016/i.molstruc.2019.127211

6.ZHANG, Q., CHEN, J., YANG, L., DONG, W., SHENG, X., ZHU, X. Structure Optimization and Implementation of a Lightweight Sandwiched Quadcopter, Intelligent Robotics and Applications. Lecture Notes in Computer Science, Springer, 9246, 2015.

https://doi.org/10.1007/978-3-319-22873-0 20

7.FERRO, C., GRASSI, R., SECLÌ, C., MAGGIORE, P., Additive Manufacturing Offers New Opportunities in UAV Research, Proceedings of 48th CIRP Conference on MANUFACTURING SYSTEMS - CIRP CMS 2015, Ischia (Naples), Italy, 24 - 26 June 2015, p.1004-1010.

doi: 10.1016/j.procir.2015.12.104

8.AHMED, N.A., PAGE, J.R., Manufacture of an Unmanned Aerial Vehicle (UAV) for Advanced Project Design using 3D Printing technology, Appl. Mech. Mater. 397-400, 2013, 970-980. doi:10.4028/www.scientific.net/AMM.397-400.970

9.BANFIELD, C., KIDD, J., JACOB, J., Design and Development of a 3D Printed UAV, Proceedings of 54th AIAA Aerospace Sciences Meeting, San Diego, California, USA, 4-8 January 2016, p.1-19. https://doi.org/10.2514/6.2016-2029 
10.MURALIDHARAN, N., PRATHEEP, V.G., SHANMUGAM, A., HARIRAM, A., DINESH, P., VISNU, B., Structural analysis of mini drone developed using 3D printing technique, Materials Today: Proceedings, in press. https://doi.org/10.1016/i.matpr.2021.04.053

11.SATRA, M.K., SHETTY, S., Design Optimization and Manufacturing of Quadcopter using 3D Printing, Proceedings of International conference on Advances in Thermal Systems, Materials and Design Engineering (ATSMDE2017), Mumbai, India, 21 December 2017, p.1-8.

12.SAGAR, N.V.S.S., ESAKKI, B., UDAYAGIRI, C., VEPA, K.S., Multistage Mass Optimization of a Quadcopter Frame. In: Gascoin N., Balasubramanian E. (eds) Innovative Design, Analysis and Development Practices in Aerospace and Automotive Engineering. Lecture Notes in Mechanical Engineering. Springer, Singapore. 2021. https://doi.org/10.1007/978-981-15-6619-6 19

13.BRIGHT, J., SURYAPRAKASH, R., AKASH, S., GIRIDHARAN, A., Optimization of quadcopter frame using generative design and comparison with DJI F450 drone frame, IOP Conf. Ser.: Mater. Sci. Eng. 1012, 2021, 012019. doi:10.1088/1757-899X/1012/1/012019

14.AHMAD, F., KUMAR, P., BHANDARI, A., PATIL, P.P., GHOSAL, A., Finite element analysis based material optimization of a quadcopter body frame, International Journal of Mechanical and Production Engineering Research and Development (IJMPERD), 8(7), 2018, 1342-1347.

15.MOSADDEK, A., KOMMULA, H.K.R., GONZALEZ, F., Design and Testing of a Recycled 3D Printed and Foldable Unmanned Aerial Vehicle for Remote Sensing, Proceedings of 2018 International Conference on Unmanned Aircraft Systems (ICUAS), Dallas, TX, USA, 12-15 June 2018, p.1207-1216. 16.ZHAFRI, Z.M., EFFENDI, M.S.M., ROSLI, M.F., A review on sustainable design and optimum assembly process: A case study on a drone, AIP Conference Proceedings, 2030, 2018.

https://doi.org/10.1063/1.5066712

17.GOH, G.D., AGARWALA, S., GOH, G.L., DIKSHIT, V., SING, S.L. YEONG, W.Y., Additive manufacturing in unmanned aerial vehicles (UAVs): Challenges and potential, Aerosp. Sci. Technol., 63, 2017, 140-151. http://dx.doi.org/10.1016/i.ast.2016.12.019

$18 * * *$ What Are Drones Made Of? Available online:

https://matmatch.com/blog/what-are-drones-made-of/ (accessed on 01.08.2021).

19.MAZURCHEVICI, S.M., PRICOP, B., ISTRATE, B., MAZURCHEVICI, A.D., CARLESCU, V., CARAUSU, C., NEDELCU, D., Technological Parameters Effects on Mechanical Properties of Biodegradable Materials Using FDM, Mater. Plast. 57(2), 2020, 215-227.

https://doi.org/10.37358/MP.20.2.5368

20.RAJIC, A., DESNICA, E., PALINKAS, I., NEDELCU, D., LAZIC VULICEVIC, LJ., 3D Printing Technology with Plastic Materials for Hip Implant Master Patterns Manufacturing, Mater. Plast. 56(4), 2019, 882-890. https://doi.org/10.37358/MP.19.4.5280

21.NEDELCU, D., COJOCARU, V., MICU, L.M., FLOREA, D., HLUSCU, M., Using of Polymers for Rapid Prototyping of an Axial Microturbine Runner and Wicked Gates, Mater. Plast. 56(2), 2019, 454459. https://doi.org/10.37358/MP.19.2.5206

22.QUAN, Q., Introduction to Multicopter Design and Control, Springer, Singapore, 2017. https://doi.org/10.1007/978-981-10-3382-7

23.PALINKAŠ, I., DESNICA, E., Determination of influence of part orientation on production time in 3D printing, Journal of engineering management and competitiveness (JEMC), 8(1), 2018, 28-36.

24.***Acrylonitrile Butadiene Styrene (ABS) Typical Properties Generic ABS, Available online: https://plastics.ulprospector.com/generics/1/c/t/acrylonitrile-butadiene-styrene-abs-propertiesprocessing (accessed on 01.07.2021).

25.***Polylactic Acid (PLA) Typical Properties, Available online:

https://plastics.ulprospector.com/generics/34/c/t/polylactic-acid-pla-properties-processing (accessed on 01.07.2021).

Manuscript received: 6.09 .2021 